\title{
Adverse effects of sports supplements in men
}

\section{Sarah J Martin \\ Sexual health physician \\ Senior lecturer ${ }^{2}$ \\ Miranda Sherley \\ Sexual health registrar ${ }^{1}$ \\ Lecturer $^{2}$ \\ General practitioner ${ }^{3}$ \\ Malcolm McLeod \\ Associate professor \\ College of Physical and \\ Mathematical Sciences ${ }^{4}$ \\ ${ }^{1}$ Canberra Sexual Health \\ Centre \\ Canberra Hospital \\ ${ }^{2}$ Australian National \\ University Medical School \\ Canberra \\ ${ }^{3}$ Bungendore Medical \\ Centre \\ Bungendore \\ New South Wales \\ ${ }^{4}$ Australian National \\ University \\ Canberra}

\section{Keywords}

anabolic steroids, androgen deficiency, hypogonadism, sport

Aust Presr 2018;41:10-13

https://doi.org/10.18773/ austprescr.2018.003

\section{SUMMARY}

Sports supplements are widely available over-the-counter and online. They may contain undeclared substances including androgenic steroids.

According to the Australian Sports Anti-Doping Authority almost one in five sports supplements contain banned substances including stimulants and anabolic drugs. It warned that any supplement may not be safe to use.

Some supplements contain large amounts of protein or creatine. Their use may cause a raised blood urea or creatinine in an otherwise healthy individual.

Androgen deficiency with symptoms of hypogonadism may be due to use of androgenic steroids. This may be inadvertent as the labels on the sports supplements may not list steroids in the ingredients.

If a person admits to using sports supplements it is an opportunity to discuss their health and fitness.

The Australian Sports Commission has advice on building muscle and the use of supplements.

\section{Introduction}

Legally obtained supplements marketed for performance enhancement are commonplace and include sports drinks, energy beverages, and a wide range of pills and powders for oral consumption. Multi-ingredient sports supplements containing taurine, creatine or other amino acids are readily available and appear to be increasingly popular.

In a 2011-12 survey, 2.9\% of Australian adults of all ages reported using a special dietary product on the day before interview. Approximately $70 \%$ of these supplements were sport and protein beverages or powder. The rate of use was $7.8 \%$ in men aged $19-30$.

People take supplements to gain muscle mass, lose weight and improve their performance or general health. They may be unaware that long-term use of supplements can have adverse effects. Supplements could potentially worsen some health conditions or interact with drugs.

Some products are contaminated with substances that are prohibited in sport. ${ }^{2-4}$ They may contain steroids that are not listed on the product label. 5,6 Australian research has found anabolic drugs or stimulants in 13 out of 67 supplements. ${ }^{2}$ It was recognised over a decade ago that some $20 \%$ of nutritional supplements sold in Europe and the USA contained anabolic steroids. ${ }^{7}$ Even products supplied by overseas pharmacies may contain prohibited substances. ${ }^{8}$ The importation of prohibited substances may also breach customs regulations.

\section{Energy drinks}

Unlike sports drinks, which are generally used as hydration fluids, energy beverages are used for their supposed performance-enhancing properties. ${ }^{9,10}$ Common energy beverages contain caffeine, taurine (an amino acid found naturally in meat and fish), $B$ vitamins and sugars. ${ }^{9}$

Caffeine has stimulant effects on blood pressure and heart rate. It can cause nervousness, irritability and sleep disturbance.

Taurine is promoted for its ability to improve exercise capacity and performance, but most energy beverages do not contain enough of it for therapeutic or adverse effects. ${ }^{9}$ Little is known about the effects of heavy or long-term taurine use.

\section{Creatine}

Creatine is derived from amino acids and produced by the liver and kidneys. It is primarily stored in skeletal muscle cells, where it serves as an energy source. Sports supplements may contain creatine alone or in combination. Creatine monohydrate has been popular for over a decade despite a lack of evidence of safety with long-term use. Supplementation may improve exercise performance in adults performing highintensity short-duration exercises, although the extent of benefit is variable." There is little evidence for the efficacy for creatine in combination products or of the safety of some of the newer forms of creatine such as creatine ethyl ester. ${ }^{12}$ 


\section{Steroids}

Some sports supplements also contain endocrine disruptors including anabolic drugs, or androgenic steroids. ${ }^{5,6,13}$ When these synthetic drugs have been developed to evade regulatory control, they are referred to as 'designer steroids'. ${ }^{6}$ In many cases these synthetic steroids have never been evaluated by regulatory bodies for purity, clinical efficacy or toxicity, so there are additional risks. ${ }^{6}$ Designer steroids are often heavily marketed as prohormones, natural steroids and testosterone boosters on websites that promote supplement use for muscle bulk and strength. ${ }^{6}$ The use of sports supplements containing steroids is a growing public health concern with evidence of increasing use among young gym attendees and men over 40 years old. ${ }^{14,15}$

\section{Androgen deficiency and supplement cycling}

Sports supplement users may engage in supplement cycles, with periods of intensive use followed by washout periods. If one or more products contain anabolic drugs, the exogenous androgens may promote muscle bulk, but will also suppress testicular testosterone production and exert negative feedback on the release of gonadotropins from the pituitary gland. ${ }^{14,16}$ Excess circulating testosterone is converted into oestradiol, providing further negative feedback to the pituitary. High concentrations of oestrogen may lead to oestrogenic adverse effects including gynaecomastia. ${ }^{14}$

At the end of a supplement cycle, the body's own testosterone concentrations may be very low. Symptomatic individuals may then use post-cycle drugs such as aromatase inhibitors, to slow the conversion of endogenous androgens to oestrogen, or selective oestrogen receptor modulators such as clomiphene and tamoxifen, to reduce the effects of circulating oestrogen. ${ }^{16}$ While these are prescription drugs in Australia, they are readily purchased online and may also be found in some supplements. There is little evidence that these approaches increase endogenous testosterone after supplement use..$^{16}$

\section{Clinical suspicions}

Some clinical presentations should prompt questioning about the use of energy beverages and sports supplements. Agitation, palpitations and insomnia, possibly in conjunction with high blood pressure, may be related to over-consumption of caffeine or energy beverages. ${ }^{9}$

Post-pubertal patients whose sports supplements contain androgenic steroids may present with features of androgen deficiency due to suppression of the hypothalamic-pituitary axis (see Fig.). Symptoms can be non-specific, such as lethargy, fatigue, low mood, irritability and poor concentration. More specific problems include male pattern hair loss, acne, liver injury, increased cardiovascular risk, osteopenia or osteoporosis, reduced muscle mass and strength, increased fat mass and gynaecomastia. ${ }^{17}$ There may be reduced sexual and reproductive function, with low libido and erectile dysfunction. ${ }^{14,18}$ Infertility may also occur. ${ }^{19}$ Other causes of hypogonadism must also be considered when making the diagnosis.

Some patients may present requesting prescriptions for drugs such as selective oestrogen receptor modulators and aromatase inhibitors. ${ }^{16}$ Consider whether this may be for the mitigation of adverse effects of androgen or anabolic steroidinduced hypogonadism.

Many users of high-protein sports supplements will be asymptomatic. However, renal function tests, done as part of an assessment for other clinical conditions, may find an incidental raised blood urea or creatinine. This should trigger an enquiry about supplement use. Supplements containing high quantities of protein may cause increased blood urea. ${ }^{20}$ Those containing creatine may lead to increased creatinine concentrations.

\section{Fig. Androgenic adverse effects in men}

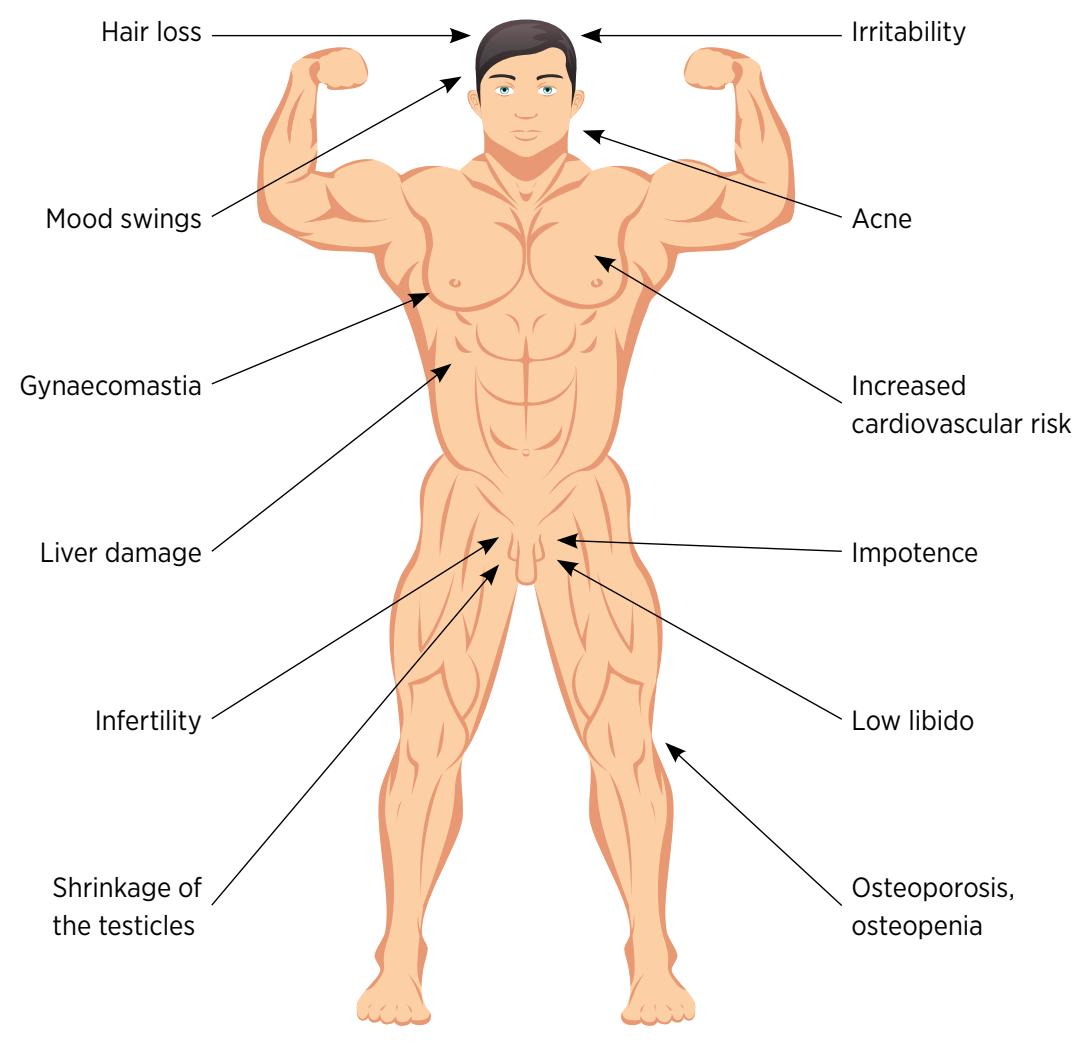


Obtaining a full history of supplement use can be complex. Multiple products are available online and may no longer be available for retrospective review of their contents. Even when details are available, the anabolic steroid content is unlikely to be listed. ${ }^{5}$ Patients who are willing to provide a comprehensive history of their supplement use may deny taking androgens, but this does not exclude inadvertent oral ingestion.

\section{Examination}

The examination of a patient suspected of supplement use should include blood pressure, height, weight, body mass index and, if obese, waist circumference. Assess facial, head and body hair distribution for deviation from the normal male pattern. Check for gynaecomastia. Scrotal examination is essential and testicular volume should be assessed, preferably with an orchidometer (normal range 15-35 mL in men aged 21-35 years). ${ }^{19}$

Consider other explanations for any abnormal findings. For example, if there is a history of headache or changes in vision in the presence of hormonal changes, check the visual fields. Headache with a visual field defect should prompt further investigation for a pituitary mass.

\section{Investigation}

When an androgen deficiency is suspected the initial hormonal assessment should include serum testosterone. If the result is low the test should be repeated at least once and gonadotropins should be measured. ${ }^{21}$ Serum testosterone is most accurately measured between $8 \mathrm{am}$ and $10 \mathrm{am}$ as concentrations may be lower later in the day (adjust timing for shift workers to shortly after waking).

In addition to sex hormone assays, a full blood count, liver and kidney function tests, and thyroid stimulating hormone may be considered as part of baseline assessment.

Secondary testicular failure (hypogonadotropic hypogonadism) due to sports supplement use is a diagnosis of exclusion and referral to an endocrinologist may be needed. Measure serum prolactin to help exclude prolactinoma or macroadenoma with pituitary stalk compression. Iron studies may exclude thalassemia and hemochromatosis. Imaging of the pituitary is indicated when there is suspicion of pituitary or hypothalamic disease.

\section{Management}

To the patient, problems resulting from sports supplements can be counterintuitive if the motivation for use is to 'get fit' and 'bulk up'. Guidance may be sought online, from blogs, peers or personal trainers rather than consultation with a GP, sports physician or nutritionist. Additionally, sports supplements are costly so are often a significant personal financial investment alongside gym equipment, gym membership and time spent working out.

Establish the patient's aims in taking supplements before reviewing and renegotiating use to reduce the risk of harm. Discussion of sleep patterns and sleep hygiene measures may be helpful for patients reliant on energy drinks. For oral protein supplement users, take a dietary history and encourage adequate but not excessive protein intake through food rather than supplements.

The Australian Sports Commission provides online advice on building muscle, protein and sports supplements. $22-24$ Consider referral to a specialist in sports medicine or a nutritionist to optimise training and diet.

For supplement users with androgen deficiency, care can be more complex, especially when a patient is reluctant to cease use for fear of losing muscle bulk, strength and endurance. Discuss the impact on fertility as well as sexual function. Encourage them to stop the supplements and repeat hormone studies in three months to demonstrate improvement in endogenous hormones. If the patient agrees to stop using supplements, and hormone studies do not normalise over six to nine months, endocrinology referral is indicated.

\section{Conclusion}

Sports supplements are ubiquitous. Their ingredients may be obscure and reasons for their use can be complex. A history of use should be sought in patients presenting with concerns about agitation, sleep, libido and sexual function, as well as infertility.

The advice of the Australian Sports Anti-Doping Authority to competitive athletes in relation to sports supplements generalises well to the broader population. Think about whether supplements are safe, effective or necessary. Similar improvements in fitness may be gained through changes in nutrition, training or sleep programs. $<$

Conflict of interest: none declared 


\section{REFERENCES}

1. Australian Bureau of Statistics. 4364.0.55.007 - Australian Health Survey: Nutrition First Results - Foods and Nutrients, 2011-12.www.abs.gov.au/ausstats/abs@.nsf/ Lookup/by\%20Subject/4364.0.55.007 2011-12 Main\%20 Features Supplements 400 [cited 2018 Jan 1]

2. Australian Sports Anti-Doping Agency. Media statement: ASADA issues supplement warning. 2016 Jun 30. www.asada.gov.au/news/media-statement-asada-issuessupplement-warning [cited 2018 Jan 1]

3. Australian supplement survey summary. LGC Limited; 2016. http://www.supplementsinsport.com[cited 2018 Jan 1]

4. World Anti-Doping Agency. World Anti-Doping Code 2015. www.wada-ama.org/en/what-we-do/the-code [cited 2018 Jan 1]

5. Cooper ER, McGrath KC, Li X, Akram O, Kasz R, Kazlauskas $R$, et al. The use of tandem yeast and mammalian cell in vitro androgen bioassays to detect androgens in internet-sourced sport supplements. Drug Test Anal 2017:9:545-52. https://doi.org/10.1002/dta.2000.

6. Rahnema CD, Crosnoe LE, Kim ED. Designer steroids - overthe-counter supplements and their androgenic component review of an increasing problem. Andrology 2015;3:150-5. https://doi.org/10.1111/andr.307

7. Geyer H, Parr MK, Mareck U, Reinhart U, Schrader Y, Schänzer W. Analysis of non-hormonal nutritional supplements for anabolic-androgenic steroids - results of an international study. Int J Sports Med 2004;25:124-9. https://doi.org/10.1055/s-2004-819955

8. Kelly B. Online pharmacies: buyer beware. Aust Prescr 2015;38:186-7. https://doi.org/10.18773/austprescr.2015.067

9. Higgins JP, Tuttle TD, Higgins CL. Energy beverages: content and safety. Mayo Clin Proc 2010;85:1033-41. https://doi.org/ 10.4065/mcp.2010.0381

10. Ballard SL, Wellborn-Kim JJ, Clauson KA. Effects of commercial energy drink consumption on athletic performance and body composition. Phys Sportsmed 2010;38:107-17. https://doi.org/10.3810/psm.2010.04.1768

11. Cooper R, Naclerio F, Allgrove J, Jimenez A. Creatine supplementation with specific view to exercise/sports performance: an update. J Int Soc Sports Nutr 2012;9:33. https://doi.org/10.1186/1550-2783-9-33

12. Jäger R, Purpura M, Shao A, Inoue T, Kreider RB. Analysis of the efficacy, safety, and regulatory status of novel forms of creatine. Amino Acids 2011;40:1369-83. https://doi.org/ 10.1007/s00726-011-0874-6

13. Deldicque L, Francaux M. Potential harmful effects of dietary supplements in sports medicine. Curr Opin Clin Nutr Metab Care 2016:19:439-45. https://doi.org/10.1097/MC0.0000000000000321
14. Rahnema CD, Lipshultz LI, Crosnoe LE, Kovac JR, Kim ED. Anabolic steroid-induced hypogonadism: diagnosis and treatment. Fertil Steril 2014;101:1271-9. https://doi.org/ 10.1016/j.fertnstert.2014.02.002

15. Joseph JF, Parr MK. Synthetic androgens as designer supplements. Curr Neuropharmacol 2015;13:89-100. https://doi.org/10.2174/1570159X13666141210224756

16. Karavolos S, Reynolds M, Panagiotopoulou N, McEleny K, Scally M, Quinton R. Male central hypogonadism secondary to exogenous androgens: a review of the drugs and protocols highlighted by the online community of users for prevention and/or mitigation of adverse effects. Clin Endocrinol (Oxf) 2015;82:624-32. https://doi.org/10.1111/ cen.12641

17. US Food and Drug Administration. Caution: Bodybuilding products can be risky. 2017 June 20. www.fda.gov/ ForConsumers/ConsumerUpdates/ucm173739.htm [cited 2018 Jan 1]

18. Yeap BB, Grossmann M, McLachlan RI, Handelsman DJ, Wittert GA, Conway AJ, et al. Endocrine Society of Australia position statement on male hypogonadism (part 1): assessment and indications for testosterone therapy. Med J Aust 2016;205:173-8. https://doi.org/10.5694/ mja16.00393

19. El Osta R, Almont T, Diligent $\mathrm{C}$, Hubert N, Eschwège $\mathrm{P}$, Hubert J. Anabolic steroids abuse and male infertility. https://www.ncbi.nlm.nih.gov/pubmed/26855782 Basic Clin Androl 2016;26:2. https://doi.org/10.1186/ s12610-016-0029-4

20. Young VR, El-Khoury AE, Raguso CA, Forslund AH, Hambraeus L. Rates of urea production and hydrolysis and leucine oxidation change linearly over widely varying protein intakes in healthy adults. J Nutr 2000;130:761-6.

21. Perry-Keene D. Low testosterone in men. Aust Prescr 2014;37:196-200. https://doi.org/10.18773/austprescr.2014.076

22. Australian Sports Commission, Australian Institute of Sport. Increasing muscle mass. Australian Sports Commission; 2009. www.ausport.gov.au/ais/sports_nutrition/fact_sheets/ increasing_muscle_mass [cited 2018 Jan 1]

23. Australian Sports Commission, Australian Institute of Sport. FAQ. Supplements in sport: why are they so tempting? Australian Sports Commission; 2017. www.ausport.gov.au/ ais/sports nutrition/supplements/supplements in sport [cited 2018 Jan 1]

24. Australian Sports Commission, Australian Institute of Sport. Protein. Australian Sports Commission; 2009. www.ausport.gov.au/ais/sports_nutrition/fact_sheets/ protein_-_how_much [cited 2018 Jan 1] 